\title{
Médicos e assistência médica: Estado, mercado ou regulação? U ma falsa questão
}

\author{
Physicians and health care: \\ state, market or regulation? \\ A false issue
}

Celia Almei da 1

\footnotetext{
1 Departamento de Administração e Planejamento em Saúde Escola Nacional de Saúde Pública, Fundação Oswaldo Cruz. Rua Leopoldo Bulhões 1480, sala 715, Rio de Janeiro, RJ 20041-210, Brasil. calmeida@ensp.fiocruz.br
}

\begin{abstract}
A cost crisis in the health care sector has focused discussion on health care services and an assessment of the results of investments in the health sector, underlining the importance of medical doctors as key actors in this area. This article revi ews the main analytical approaches to professionalism in the last decade and discusses the most recent paradigmatic shifts. New approaches have emerged for correlating the medical division of labor (contained in specialized fields which are becoming more and more fragmented) with structural and historical changes in the professional market, as well as the collective action devel oped by these interest groups in their relationship to the state. These approaches, more cl osely linked to political economy, have made important contributions to this debate, because they allow for a questioning of the kind of ideological polarization contained in health care reform proposals aimed at a withdrawal of the state and the rule of the market (with no analytical justification), in addition to shifting regulation to a position outside the historically mutable dynamics between the state, health care providers, and clients of the health care sector and the public policy arena.

Key words Physicians; Medical Assistance; Health Personnel; Health Policy
\end{abstract}

Resumo A crise de custos no setor saúde colocou em discussão a assistência médica, assim como a avaliação dos seus resultados enquanto investimento setorial, sen do que a importância do principal ator nessa dinâmica - o médico - tem si do ressaltada. Este artigo faz uma revisão das princi pais vertentes de análi se do profissionalismo médi co nas últi mas décadas e discute a mudança de paradigma que se operou mais recentemente, quando emergem enfoques que procuram correl acionar as novas di visões de trabal ho conti das nas especializações cada vez mais fragmentadas com as mudanças estruturais históricas do mercado de trabal ho profissional e a ação col etiva desenvolvida por esses grupos na sua inter-rel ação com o Estado. Esse último enfoque, pode-se dizer mais vinculado à economia política, tem aportado importantes contribuições a esse debate, uma vez que permi te questionar as polarizações i deológi cas, esem fundamento analíti co, presentes nas propostas de reforma da assistência médica, que preconizam a retirada do Estado e o reinado do mercado, assi m como desl ocam a regulação para uma posi ção externa à própria dinâmica, mutável histori camente, das relações Estado/profissi onais/cl ientes/sistemas de saúde.

Palavras-chave Médicos; Assistência Médica; Pessoal de Saúde; Política de Saúde 


\section{Introdução}

Historicamente, a oposição Estado versus mercado tem dominado as discussões no campo sanitário e está subjacente tanto aos cálculos racionais que presidem os interesses dos diferentes atores na arena setorial, quanto aos amplos conflitos ideológicos e político-partidários que têm acompanhado o debate sobre o tema nos diversos países.

O impacto da política de saúde nos mercados de assistência médica pode ser um guia efetivo para entender qual o significado histórico desse conflito recorrente, assi m como para ajudar a elucidar quais são suas bases de suporte e permanência no tempo.

Essas disputas, para Immergut (1992:35), estão centradas no conflito clássico entre compradores e vendedores, neste caso de serviços de assistência médica. Ou seja, o poder de compra de um é utilizado para reduzir e controlar preços, sendo reforçado quando se torna o único comprador (numa posição monopsônica); e o poder de venda do outro tende a se concentrar de forma monopólica, fortalecendo-se quando consegue diversificar os compradores de serviços.

A expansão do papel do Estado na área da saúde, sobretudo no pós-guerras, significou, para os seus defensores, a responsabilização do Estado pela garantia do acesso aos serviços como um direito de cidadania e, para os seus oponentes, a expropriação da responsabilidade individual pela própria saúde, uma enorme drenagem de recursos e um sério impedimento (ou restrição) ao pleno funcionamento do mercado privado no setor.

Vale a pena recuar um pouco na história para iluminar alguns aspectos desse processo. Os esforços para consolidar financiamentos coletivos para a atenção médica, a partir do final do século XIX, trouxe para a agenda política a questão do mercado versus Estado, oposição esta que tem mudado de significado no tempo, segundo o período histórico e a conjuntura específica de cada época, em cada sociedade. A questão objetiva da propriedade pública versus a privada mudou significativamente na medida em que o financiamento estatal passou a garantir grande parte da atenção hospitalar nos dois setores - público e privado. E devese estar atento aos rótulos ou vinculações de um e outro com determinadas propostas a filiações ideológicas específicas, pois ainda que no plano das idéias essa associação seja possível, a reação às políticas formuladas em períodos específicos e as estruturas institucionais que viabilizam as respectivas implementações são muito mais complexas e não se confundem com a história das correntes ideológicas, ainda que profundamente influenciadas por elas.

Assim, especificamente no que diz respeito à expansão dos programas de assistência médica do wel farestate, esta teve pelo menos duas implicações aparentemente contraditórias: de um lado aumentou os recursos financeiros disponíveis para prestar assistência a grandes parcelas da população que de outra forma não poderiam pagar por ela, ao mesmo tempo que aumentou a regulação e o controle públicos sobre os prestadores de serviços, sobretudo os médicos.

Mesmo se considerarmos diferentes sistemas 'tipo-ideal', o controle público sobre as formas de financiamento e/ ou de pagamento dos prestadores e o fortalecimento da capacidade regulatória (pública e privada), ainda que concomitantes à ampliação de mercado, são componentes estratégi cos desses desenvolvimentos. Além disso, a dimensão mais imediata da noção de intervenção estatal diz respeito “às formas eà intensidade em que ela afeta o controle privado dos serviços de saúde" (Donnangelo, 1975:4).

Embora sejam descritas na literatura várias maneiras pelas quais o Estado e os prestadores (sobretudo médicos) resolveram suas diferenças nesses confrontos através do tempo, podese dizer que, durante o período de rápida expansão da assistência médica na Europa (de 1930 a 1970), basicamente uma estratégia principal foi utilizada pelos prestadores em todos os casos. O modelo liberal da medicina sempre defendeu o livre mercado como o corede proteção de sua autonomia: lutaram contra a entrada do Estado no mercado de seguro-doença, contra os esforços subseqüentes de controlar os custos regulando os honorários e mudando os métodos de pagamento para formas mais coletivas (como o assalariamento) e contra as proibições da prática privada para médicos empregados no setor público. A independência do médico sempre foi enfatizada como condição necessária para assegurar a qualidade da atenção, pois, seguindo o exemplo da mais pura tradição liberal ("a independência econômica como pré-condição para a liberdade política" (Friedman, 1962)), a autonomia econômica do médico sempre foi considerada essencial para alcançar resultados não econômicos, isto é, liberdade terapêutica, confiança do paciente, liberdade em relação à burocracia, manutenção da assistência médica como uma 'arte interpretativa', em que a conduta terapêutica deve seguir as necessidades individuais do paciente e não as diretrizes governamentais, e controle 
do profissional sobre o conteúdo e o tempo de seu próprio trabalho (Donnangelo, 1975; Immergut, 1992). Portanto, a autonomia técnica se imbrica com a autonomia econômica.

Sendo assim, a luta dos profissionais sempre foi norteada pelas tentativas de prevenir a posição monopsônica do Estado, rotulando determinado aspecto do mercado de assistência médica como privado e defendendo a sua preservação: ao manter abertas diferentes formas de prática privada nos sistemas de saúde, paulatinamente dominados pelo financiamento e pelas formas de pagamento público, a profissão protegia sua habilidade de sair do setor público, como uma alternativa estratégica.

$\mathrm{Na}$ realidade, a possibilidade de 'bolsões' de prática privada no setor público é de fato causada pela própria dinâmica econômica de estruturação dos sistemas de assistência médica: ao subsidiar esse mercado, o Estado aumentou a demanda por esses serviços mas, ao mesmo tempo, ao pressionar os preços para baixo e controlar seus valores, criou pressões de mercado para o aumento da oferta, que por sua vez, proporcionou as oportunidades para o setor privado. Portanto, a estruturação dos sistemas de assistência médica tal como os conhecemos hoje se deu através de profundo imbricamento entre o público e o privado.

Em síntese, a luta pela manutenção de financiamentos pluralísticos, com nichos privados de mercado, e contra a regulação pública, integra a própria história de consolidação do modelo médico liberal, num específico período, quando a autonomia econômica tornou-se condição necessária para a autonomia profissional. Ironicamente, a partir dos anos 80, pareceria que o Estado defendia o livre mercado na assistência médica, exatamente para controlar a autonomia profissional.

Entretanto, essas duas dimensões da autonomia profissional não podem ser confundidas - como apontou Freidson, sobretudo a partir do início do século XX, quando novas fragmentações são introduzidas na dinâmica da prática médica, seja com o desenvolvimento das especializações cada vez mais numerosas, ou com a diversificação das posições de mercado ocupadas pelos profissionais - com o desenvolvimento dos serviços de assistência médica alavancados pelo Estado (médicos assalariados do setor público, de seguradoras, privados, conveniados, credenciados, etc).

Portanto, é preciso distinguir analiticamente as questões clássicas do profissionalismo, tais como o processo histórico pelo qual a medicina se estabeleceu como ciência (consolidando as chamadas 'fronteiras cognitivas' da profissão e os esforços políticos para estabelecer o monopólio legal da prática), das lutas posteriores sobre issues econômicos, assim como das novas questões colocadas pela crise do welfare e as reformas setoriais mais recentes.

A profunda complexificação atual da prática assistencial e dos sistemas de serviços de saúde é acompanhada de reorganizações das representações dos grupos de interesse tradicionais e da emergência de novos, que passam a disputar parcelas do mercado de assistência médica, especialmente privilegiado sobretudo no período após a II Grande Guerra, e atuar como grupos de interesse e de pressão nas diversas arenas setoriais - acadêmica, produtiva (de serviços e de insumos), legislativa.

Logo, cada sistema de serviços de saúde, antes de ser o resultado de um desenho prédefinido, é o produto de uma infinidade de enfrentamentos, negociações e ajustes entre a burocracia estatal, a categoria médica, os sindicatos, os partidos políticos, os parlamentos e os poderosos grupos de interesse que gravitam em torno da indústria da assistência médica. A evolução das experiências nacionais mostra de fato que os sistemas de saúde são construções surgi das de complexos arranjos produtores de políticas que resolvem al guns problemas contingentes, mas incubam novos conflitos que, cedo ou tarde, afloram (Labra \& Buss, 1995; Labra, 1995a e b).

Embora o médico seja o profissional nuclear dos sistemas de saúde, e seja fato que, em todos os países capitalistas do Ocidente, o papel desempenhado pela corporação médica organizada na sua relação com o Estado é central na definição dos modos como a assistência médica é remunerada, os serviços são financiados e incorporados à cultura nacional, igualmente relevante para compreender a estruturação e dinâmica dos sistemas de saúde são as características dos respectivos estados nacionais e a forma como as diferentes instituições políticas produzem as variações nos respectivos programas setoriais. Em outras palavras, como oferecem diferentes oportunidades e/ ou barreiras à participação/ pressão dos grupos de interesse na arena setorial, possibilitando ou não, o encaminhamento de suas demandas ou abrindo espaço para os 'pontos de veto' às políticas governamentais (Immergut, 1992).

O legado das políticas passadas (seja de sucesso, seja de fracassos) afeta as políticas subseqüentes, e a questão das estratégias de reforma sanitária a serem adotadas para provocar transformações deve levar em consideração a herança dos arranjos institucionais que será confrontada com a mudança. 
A provisão direta de serviços pelo setor público politizou a relação entre os prestadores e o Estado, uma vez que as condições de trabaIho devem ser reguladas e os mecanismos de controle e contenção de preços acionados. Por outro lado, quando o Estado não emprega diretamente os prestadores, o tipo de contrato e o método de pagamento utilizado passam a ser cruciais, eas diversas formas de financiamento e pagamento de serviços, que em geral integram os sistemas mistos, fragmentam a atuação estatal e diminuem (ou complexificam) a capacidade reguladora, introduzindo outra forma de politização. Nos sistemas majoritariamente privados, a regulação envolve, de forma importante, vários outros atores, inclusive aqueles não especificamente setoriais. E essa politização foi profundamente questionada nos anos 80, constituindo a especificidade dos processos reformadores setoriais que foram desencadeados a partir de então.

O objetivo deste artigo é discutir a especificidade política e historicamente variável da inserção do profissional médico na estruturação/ reforma dos sistemas de serviços de assistência médica. Por meio da revisão da bibliografia especializada, analiso as fronteiras mutantes da regulação profissional e das relações Estado/profissão médica na formulação/implementação das políticas de saúde. Nesse percurso, aponto o indisfarçável tom ideológico presente nos debates atuais sobre as propostas de reforma da assistência médica, que, por um lado, deposita nos médicos a carga maior de culpa pelos problemas enfrentados pelos sistemas de serviços e, por outro, preconiza o afastamento do Estado das questões referidas à assistência médica a ser prestada à população.

\section{Profissionalismo e autonomia dos médicos}

O estudo sobre os médicos sempre foi particularmente contemplado nas pesquisas voltadas para a sociologia das profissões, mas nas últimas décadas tem merecido atenção especial, inclusive de outras áreas com diferentes recursos disciplinares. Por um lado, pela importância que a participação desses profissionais na estruturação dos modernos sistemas de serviços de saúde adquiriu historicamente e, mais recentemente, por serem responsabilizados por grande parte das mazelas que afligem a assistência médica nos diversos países: altos custos dos serviços, descontrole nos mecanismos gerenciais, desperdício de recursos, iatrogenia etc.
A crise de custos na saúde colocou em discussão o funcionamento dos serviços de saúde, sobretudo a assistência médica, e a avaliação dos seus resultados, e inúmeros são os trabalhos que apontam a importância do principal ator nessa dinâmica - o médico -, sobretudo no que concerne à sua capacidade de interferir na organização e funcionamento dos sistemas, tanto pelo lado da oferta, como pelo da demanda, assim como a sua grande resistência a enquadrar-se em qualquer preceito normativo, visto sempre como cerceador de sua liberdade de julgamento e interferência indevida na sua prática profissional - isto é na sua autonomia.

Como ponto central do debate está o específico profissionalismo presente na atenção à saúde, assim como a mudança de status profissional e credibilidade que significou o processo de erosão de sua autonomia e o crescente assalariamento do médico (ou desprofissionalização, proletarização e corporatização, respectivamente), desenvolvimentos ocorridos fundamentalmente neste nosso século, em todas as sociedades modernas.

Paralelamente à maior atenção dos estudiosos para com essa temática, tem-se verificado também um deslocamento do paradigma teórico (Speranza, 1991). Com base na crítica da perspectiva estrutural-funcionalista - que analisa o desenvolvimento das reestruturações, provocadas pelas novas divisões do trabalho contidas nas permanentes especializações profissionais, como resposta a necessidades sempre crescentes (na sociedade) de conhecimentos cada vez mais complexos -, passa-se a enfoques que procuram correlacionálas com as mudanças estruturais históricas do mercado de trabalho profissional e a ação coletiva desenvolvida por esses grupos na sua inter-relação com o Estado. Esse último enfoque, pode-se dizer mais vinculado à economia política, tem aportado importantes contribuições a esse debate e o percurso teórico dessa passagem é analisado por vários autores (Donnangelo, 1975; Wolinsky, 1988; Light \& Levine, 1988; Larkin, 1988; Coburn, 1992; Speranza, 1991, entre outros).

Até os anos 60, os enfoques classificatórios baseados na definição de atributos e funções, que distinguem as áreas profissionais dos demais campos de trabalho da sociedade, dominaram a cena da sociologia das profissões. Nessas vertentes de análise, o que distinguia as profissões era a existência de uma base de conhecimento científico abstrato e a adesão a um ideal ético-moral de serviço altruístico, atributos estes funcionalmente essenciais à socieda- 
de. No campo sanitário (onde a profissão médica é considerada a profissão por excelência) esta perspectiva traduziu-se na percepção de que os conhecimentos médicos eram indispensáveis para curar as pessoas, cujo bem-estar físico era condição essencial para a manutenção do desenvolvimento da sociedade; sendo assim, as atividades médicas constituiriam um requisito funcional essencial para a sociedade.

Inúmeras foram as críticas que apontaram as incongruências teóricas deste tipo de análise (Becker, 1963, 1964, 1970; Hughes, 1971; Klegon, 1978; Sacks, 1983), sendo duas as principais: a sua ahistoricidade e uma certa ingenuidade sociológica ao assumir-se acriticamente como interpretação da realidade a imagem que a profissão têm de si mesma, fundada num silogismo abstrato - as profissões por definição tem uma ética moral de utilidade pública, a medicina é obviamente uma profissão, em conseqüência deve ter um ideal de servir à população (Björkman, 1990; Speranza, 1991).

As indagações sobre as circunstâncias sociais nas quais uma certa ocupação busca, mediante estratégias específicas, obter os privilégios e o poder aferidos ao status profissional datam dos anos 70 e vários autores apontam Freidson (1970a e b) como seu principal formulador. Ressaltando que as características até então assinaladas tiveram um valor analítico para a definição das profissões, Freidson propõe uma redefinição que leve em consideração o poder e o controle social, ou seja, uma reconceituação em termos de uma autonomia legitimada e organizada socialmente, que assegure às profissões uma posição dominante na divisão de trabalho.

Segundo Wolinsky (1988), Coburn (1992) e Speranza (1991), entre outros, em uma série de trabalhos bastante provocativos, Freidson desenvolveu a teoria que ficou conhecida como a perspectiva da dominância profissional. Sua análise se inicia com o argumento de que uma profissão deve ser definida como uma ocupação que adquiriu autonomia e autogoverno e que é organizada formal mente através de instituições criadas especialmente com o objetivo de proteger e garantir essa autonomia.

Para o autor, em qualquer segmento de trabalho, somente uma profissão pode ocupar o lugar dominante e, na 'indústria dos serviços de saúde', a única profissão que adquiriu tal autonomia organizada foi a de médico, daí seu status privilegiado (Wolinsky, 1988:34-5). Paradoxalmente, a autonomia do médico é sustentada pela dominância que seus experts exercem na divisão de trabalho, o que se constitui numa distinção crucial, ou seja, uma relação estrutural inteiramente diferente na divisão de trabalho setorial, que possibilita o poder de avaliar o trabalho dos demais sem ser objeto de direção formal ou avaliação por eles (Wolinsky, 1988:35, com base em Freidson). A diferença está posta, portanto, no fato de que a profissão médica adquiriu autonomia.

Essa dominância profissional significa para Freidson que os médicos controlam tanto o conteúdo de sua própria função, quanto o de outras ocupações que participam na divisão de trabalho em campo sanitário, além de que exercem poder também sobre os pacientes e sobre os termos e condições de suas atividades profissionais. Em síntese, o conceito de dominância profissional em Freidson pressupõe essas quatro diferentes dimensões, sendo a autonomia (controle sobre o conteúdo do trabalho) sua característica central (Coburn, 1992).

Quais os fundamentos da obtenção dessa autonomia e como ela se mantém?

A aquisição desse status diferenciado envolve dois estágios. Primeiro, enquanto uma profissão que proporciona consultas altamente especializadas, deve demonstrar que desenvolve um trabalho realmente confiável e valioso e persuadir o público de sua eficácia (o que não aconteceu antes do século XIX); pressupõe, portanto, o convencimento da sociedade de que determinado trabalho profissional é imprescindível e deve ser controlado por quem entende do assunto. Isto foi facilitado pela obtenção do monopólio legal sobre o estabelecimento de requerimentos educacionais, licenciamentos para o exercício profissional, código de ética, constituição de associações e alguns elementos de controles por pares. E, segundo, a concessão da autonomia, que pressupõe a inter-relação entre os poderes político e econômico e as representações profissionais. Portanto, a fundação da autonomia profissional é claramente um processo político e social de concessão legal, não algo que as profissões podem obter por si próprias, e, sendo conferida à profissão pela sociedade, leva, por sua vez, à autoregulação, além de que envolve o Estado no estabelecimento e manutenção da proeminência profissional.

A influência da medicina na organização de serviços de saúde e na política de saúde deriva, para Freidson, do monopólio da medicina científica na definição de doença, restringindo a discussão dos serviços de saúde a uma particular forma de ver a saúde: mecanicista, individual ista e orientada para a cura das doenças segundo o modelo médico. O autor questiona também que, embora essa dominância tenha levado ao avanço do conhecimento científico, 
impediu a sua aplicação efetiva em prol da melhoria das condições de saúde da população.

Apesar de bastante inovadora à época e sintonizada com o clima crítico de então, durante os últimos vinte anos, a reflexão freidsoniana tem recebido diversas críticas, às quais o autor sistematicamente respondeu, além de que vem sendo suplementada (ou suplantada) por várias outras reflexões, ampliando-se em muito o debate sobre a temática em pauta.

Três dessas críticas foram especialmente enfatizadas: a da desprofissionalização, a da proletarização e a da corporatização dos médicos:

1) A teoria da desprofissionalização é defendida basicamente por Haug (1973, 1981, 1988), que, reagindo às idéias de Bell (1976) de que as sociedades pós-industriais seriam completamente profissionalizadas, analisa que, ao contrário, a desprofissionalização seria a tendência do futuro, e avalia que existem evidências inequívocas da mudança de status dos médicos e da medicina em muitos países industrializados, traduzida nas perdas do monopólio do conhecimento, da imagem positiva que contém motivos altruístas e da capacidade de impor suas próprias regras.

A autora (Haug) aponta pelo menos cinco razões para esse declínio. O monopólio médico sobre o corpo de conhecimento que os médicos manipulam teria sido desmontado pelos seguintes fatores: a) informatização e conseqüente maior difusão de informações; b) maior nível educacional da população, o que permite ao leigo maior acesso a esse conhecimento especializado, além de insatisfação com os atendimentos recebidos e, portanto, mai or questionamento da população em relação aos profissionais; c) crescente especialização da medicina e novas formas de agregados especializados teriam tornado os médicos mais dependentes de seus colegas, assim como de outros profissionais paramédicos e experts não-médicos, reduzindo-se o poder tanto individual, quanto coletivo da categoria; d) crescimento dos grupos de consumidores e de auto-ajuda em assuntos de saúde, assim como dos inúmerose variados novos profissionais não necessariamente médicos, que trabalham com saúde nas mais diferentes bases de conhecimento e, por fim, e) denegridor ataque à altruística imagem dos médicos com a divulgação dos sempre crescentes aumentos de custos da assistência médica, colocando em dúvida a responsabilidade e comprometimento destes profissionais com os bens públicos.

Em síntese, os teóricos da desprofissionalização argumentam que a distância entre o co- nhecimento especializado e os consumidores diminuiu e que estes agora não confiam mais na medicina como antes. Ao mesmo tempo que os médicos estariam sendo obrigados a dividir seu poder monopólico (interna e externamente à profissão, com outros experts e managers), a medicina estaria perdendo seu prestígio público, tanto pela ação da crescente especialização, do aumento da iatrogenia que sua atuação especializada provoca (pelo uso indiscriminado de uma tecnologia sem avaliação cuidadosa de resultados), quanto pela difusão da idéia de que os médicos estariam mais preocupados com seu próprio bolso do que com a saúde dos seus pacientes.

Freidson (1985) contra-argumentou que a medicina não perdeu nem o respeito público, nem seu monopólio profissional e, se houve alguma perda de prestígio, foi em termos relativos, isto é, uma perda igual à que sofreu qualquer outra instituição nas décadas recentes. Por outro lado, o processo de especialização e de incorporação tecnológica é muito mais rápido que a difusão leiga do conhecimento especializado e, sendo assim, o gap entre um e outro teria aumentado e não diminuído. Além disso, a incorporação tecnológica e a inclusão de novos operadores e profissionais não dispensa jamais o aval final do médico, não enfraquecendo, portanto, sua posição de controle. Por fim, e não menos importante, nenhuma das expressões de desconfiança e desrespeito, ou mesmo os movimentos de consumidores em saúde (como os de vítimas de malpractice ou erro médico, negligência ou imperícia), atingiu as práticas institucionais estáveis que sustentam a posição do médico: para o autor, a proeminência legal e dominância institucional da profissão mantêm-se intactas.

De qualquer forma, de fato é inegável que o movimento feminista na saúde, ou o movimento dos consumidores e lesados por atos médicos e vários outros movimentos sociais iniciaram importante mudança cultural que tem alterado hábitos sanitários, favorecido novas técnicas para gerenciar fatores de riscos ou monitorar a qualidade da assistência, tendo mesmo alterado a prática médica em alguns assuntos. Por outro lado, a informática tem possibilitado estabelecer padrões e normas de práticas consideradas aceitáveis, comparações que permitem ainda identificar os desviantes e, embora Freidson possa ter razão em termos globais, o efeito líquido é sem dúvida uma maior racionalização e monitoramento da perícia profissional; dessa forma a performance médica pode ser sujeita a avaliação externa. 
2) A segunda crítica à teoria do domínio profissional de Freidson é a da proletarização das profissões e se refere às mudanças nas condições de trabalho dos profissionais nas últimas décadas, sobretudo no que concerne ao assalariamento por grandes organizações. A teoria da proletarização dos médicos é uma reflexão feita primeiramente por McKinlay (1977), resultado de uma provocativa revisão do trabal ho de Freidson, no esforço de entender as transformações institucionais que afetam os centros médicos e a profissão, mas que tem suas bases teóricas no debate que se estabelece entre autores marxistas, weberianos e liberais sobre a natureza do trabalho profissional nas economias avançadas.

A crítica central a Freidson é exatamente não ter levado em consideração as relações entre a profissão médica e o capital ismo, os interesses de classe presentes no profissionalismo, assim como as conseqüências políticas e econômicas da medicalização, uma vez que a medicina tem apenas um modesto impacto na saúde da população (McKinlay \& Archer, 1985). Na seqüência dessa argumentação, vem a interpretação de que a expansão capitalista da medicina, em grandes organizações complexas, induziu à sua burocratização, como a principal forma de controle social, sendo que o crescente assalariamento dos médicos submete o profissional a normas regulatórias e hierarquias administrativas que de fato modelam a distribuição de serviços. Além disso, os autores afirmam que o rápido crescimento do número de médicos enfraqueceu seu poder de mercado e fortaleceu o dos burocratas, atrelando os profissionais a organizações que fogem ao seu controle. Afirma-se, dessa forma, a tendência de cada vez mais os médicos serem obrigados a trabalhar em instituições e organizações complexas, cuja racionalidade se impõe sobre qualquer trabalhador.

McKinlay \& Archer (1985), entre outros, transferem para as profissões a análise do capitalismo e sua tendência monopólica, situação em que os trabal hadores (sejam profissionais ou não) vêem-se reduzidos virtualmente ao status de proletários, que dependem da venda de sua força de trabalho para sobreviver, privando-se de qualquer controle sobre o processo de trabalho; relaciona a proletarização das profissões ao corporativismo, que acarretaria a perda das prerrogativas profissionais, uma vez que, como empregados de grandes organizações, os médicos são apenas mais um tipo de trabalhador que têm de submeter-se à racionalidade institucional imposta (McKinlay \& Stoeckle, 1988). Mechanic (1991), por sua vez, aceita que as corporações submetem os seus empregados às suas regras, mas faz a ressalva de que nem todas as corporações funcionam dessa mesma forma, enquanto Navarro (1988) refuta a idéia de que os médicos e seus representantes profissionais atuem da mesma maneira que os trabalhadores em geral, opinião compartilhada pelo próprio Freidson na sua contestação a estas críticas.

Respondendo a essas análises, Freidson contra-argumenta que, embora seja real o movimento de assalariamento (para os médicos, pelo menos, pois os outros profissionais sanitários sempre foram assalariados), assim como o da burocratização, essas tendências não significaram alterações profundas na questão central da dominância profissional: ainda que individualmente os médicos possam ter sua autonomia cerceada, a autonomia da profissão continua intacta. Em essência, Freidson reconhece as modificações apontadas por esses teóricos, mas enfatiza que são mudanças internas à profissão e não externas a ela. Ou seja, a medicina retém seu poder essencial.

Por outro lado, vários autores chamam a atenção sobre as três maiores mudanças setoriais sublinhadas pela teoria da proletarização: a crescente complexidade técnica e organizacional da medicina moderna, que é amplamente difundida pelo mundo (Larkin, 1988; Light \& Schuller, 1986); o aparecimento e rápido crescimento das grandes corporações de assistência médica (particularmente grandes cadeias de hospitais) (Light, 1986), que tentam atrair os profissionais com mais comodidades e apoio institucional ou arriscam perdê-los para os competidores não lucrativos; a revolta dos compradores institucionais de serviços (os chamados terceiros pagadores), que, a partir dos meados dos anos 70, passam a tentar controlar os alarmantes custos da assistência médica.

Ainda que subjacentes à discussão da proletarização, estas problemáticas não são passíveis de ser analisadas com o arsenal teórico da teoria da proletarização. Ao contrário, levantam a questão da pertinência e aplicabilidade do conceito de proletarização à profissão médica ou mesmo para explicar as temáticas postas pelas transformações no campo sanitário, o que é apontado também por autores marxistas, como Navarro (1988), que, apesar de tudo, admite que os médicos não perderam o controle sobre os meios de produção do seu trabalho, vale dizer, sua autonomia.

De uma maneira geral, este enfoque, de base marxista, suscitou muita polêmica e vários são os autores que exploraram essa vertente de análise e que têm procurado novos conceitos 
que permitam melhor explicar a posição dos profissionais e outros grupos nas sociedades modernas. Entre nós, merecem menção os estudos de Donnangelo (1975) e Donnangelo \& Pereira (1976), considerados clássicos.

Para os efeitos deste trabalho, basta registrar que vários autores têm compartilhado o problema teórico de tentar considerar o papel dos managers e dos doutores empregados pelas corporações, assim como as relações entre carreiras médicas e capital, plusvalia e meios de produção, inter-relacionando conceitos teóricos que pretendem desvendar as transformações e que passam bem longe da perspectiva da proletarização.

3) Finalmente, a terceira crítica à dominância profissional é a tese da corporatização (referida ao empresariamento das atividades médicas), que acompanha a teoria da proletarização, mas a partir de outro referencial teórico, mais relacionado às teorias da administração e gerenciamento das organizações complexas (McKinlay \& Stoeckle, 1988). Refere-se ao fato de os médicos terem cada vez mais de ser empregados e se sujeitar a formas de controle das grandes organizações/instituições, tais como, revisão de utilização ou qualidade, incentivos através de diferentes estruturas de remuneração, restrição a práticas-padrão; de terem de aceitar a organização da sua prática segundo esses parâmetros e enfrentar a reestruturação do mercado de serviços de saúde que significou a passagem de profissionais autônomos para pequenos grupos de provedores e daí para empregados de grandes complexos multiinstitucionais ou multiempresariais (Burnham, 1984; Stoeckle, 1988, apud Light \& Levine, 1988:19), tendo ao mesmo tempo que submeterem-se aos desígnios dos managers.

A corporatização diz respeito também ao paradoxo dos médicos dependerem de organizações complexas e de mecanismos de financiamento para desempenhar seu sofisticado trabalho, aceitando ainda que essas instituições interfiram nele, medeiem suas relações com os pacientes e, potencialmente, ameacem a sua credibilidade perante a sociedade como um todo, uma vez que a legitimidade é ao mesmo tempo expandida e ameaçada, pois que subsumida nos objetivos globais da organização.

Embora se atribua à corporatização a emergência de fenômenos relacionados com a burocratização e a racionalização, não existem evidências teóricas ou empíricas de que essa relação seja direta, além de que a tradicional ênfase na autonomia e independência que acompanha a formação dos médicos faz com que, em princípio, não estejam preparados pa- ra trabal har nas grandes estruturas organizacionais do moderno mundo industrial. Mas, o que parece ocorrer nas grandes corporações, com a aparência de racionalização e de burocracia, é o que foi denominado 'proletarização ideológica' (Derber, 1982:169-87, apud Light \& Levine, 1988:19), que “significa perda decontrole sobre o produto ou fins do próprio trabalho enquanto mantém o controle sobre os meios ou técnicas de trabal ho" (Light \& Levine, 1988: 19).

Alguns autores avaliam que há uma acomodação profissional a essa nova situação, na qual os médicos se dissociam dos objetivos institucionais e/ ou negam que o controle sobre os resultados de suas atividades interfira no seu próprio trabalho.

O conceito de corporatização tem também outra dimensão que se refere aos impulsos empresariais internos à própria profissão, muito difundidos por toda parte, uma vez que os médicos cada vez mais transformam seus consultórios em centros ambulatoriais capital-intensivo para diagnósticos e tratamentos, inclusive desviando serviços dos hospitais.

O impacto desses desenvolvimentos na profissão médica e na dominância profissional tem sido muito descrito mas não profundamente anal isado e explicado teoricamente. Nos diferentes arranjos institucionais e organizacionais existentes hoje no campo da assistência médica, as relações dos médicos em diferentes posições em relação ao capital e ao lucro, assim como a interferência dessa situação na autonomia profissional e nos resultados de seu trabaIho ainda precisam ser mais bem estudadas.

Alguns autores consideram as análises de Freidson imprecisas e confusas, já que os conceitos de autonomia e dominância sugerem níveis diversos de controle, cujas dimensões não teriam sido adequadamente especificadas nas suas reflexões (Coburn, 1992). Coburn, por exemplo, argumenta que a realidade evidencia uma situação muito mais complexa na divisão de trabalho em saúde e muitas das discussões sobre o declínio do poder médico referem-se precisamente à perda de controle profissional sobre o contexto da atenção médica e, em certa medida, sobre os clientes. Por outro lado, as inter-relações da medicina com as demais instituições societais, que faltam na maioria dessas análises, impedem a percepção da transformação do seu papel com o desenvolvimento econômico e social, assim como a mudança que se operou com a crise econômica, quando o demolidor ataque neoliberal à organização do trabalho médico nos sistemas de serviços de saúde teve como finalidade última restringilos e conter seus custos. 
Em síntese, pode-se dizer que os quatro conceitos aqui repassados sumariamente - dominância profissional, desprofissionalização, proletarização e corporatização - iluminam, cada um deles, importantes desenvolvimentos na prática médica moderna, mas refletem perspectivas teóricas e políticas que capturam apenas uma parte do problema. Sendo assim, trabalhar de forma interconectada pode possibilitar novas perspectivas teóricas com maior poder explicativo (Light \& Levine, 1988).

De qualquer forma, pode-se identificar um consenso entre os autores quanto à resistência dos médicos, através de diferentes estratégias, a submeterem-se à proletarização ou perda de controle sobre a sua profissão.

Em essência, o argumento central permanece, ou seja, o core do poder médico - autonomia técnica, habilidade em controlar seu trabalho e o de outros no setor, monopólio sobre a 'cura' das doenças - continua intacto. A medicina ainda pode lançar mão de muitas fontes de poder para vetar ou direcionar as mudanças que não sejam de seu interesse, pelo menos enquanto a profissão for dominante no setor e tiver o monopólio sobre a provisão de serviços de assistência médica, monopólio este que vem sendo sistematicamente desafiado par i passu com a escalada neoconservadora. A questão central que continua em pauta com o aumento da intervenção (ou regulação) dos governos federais (e de forma similar dos demais seguradores e terceiro-pagadores) é se esse poder é o mesmo do passado e qual a dinâmica política que de fato está produzindo mudanças na sua posição social.

\section{A percepção dos médicos como grupo de pressão e interesse}

As análises críticas da bibliografia sobre o profissionalismo médico trouxeram também uma outra contribuição importante, que é a percepção do profissionalismo médico como uma modalidade, entre outras, de controle ocupacional (Jonhson, 1972, apud Speranza, 1991: 479), através da qual se exprime um projeto profissional que consta de dois processos: um de criação e controle de mercados de serviços profissionais e outro de mobilidade social coletiva (Larson, 1977, apud Speranza, 1991:479).

Com base nessa perspectiva, as profissões, com suas associações representativas, não são mais consideradas apenas como portadoras de uma ética social superior e de um conhecimento científico especializado e, como tal, funcional mente necessários à reprodução do sistema social, mas sim como "grupos de interessee/ou de pressão não transitórios" que agem também em função da proteção de seus próprios interesses (Freidson, 1970a e b) e que trabalham em colaboração tão estreita com o governo, que torna-se difícil distinguir onde terminam as atividades de um e começam as do outro (Björkman, 1982:423).

Alguns autores consideram as associações profissionais como "arenas preliminares dele gislação pública” (Gilb, 1960:140, apud Speranza, 1991:480), uma vez que são elas que elaboram os projetos de lei setoriais; além disso, quando uma lei referente à área profissional chega ao Congresso, as escolhas e definições mais importantes já foram estabelecidas nos acordos fechados nos fóruns pré-legislativos. Daí que a maior influência das organizações profissionais é exercida nas comissões técnicas específicas, que estabelecem padrões profissionais, têm composição restrita e executam um trabalho que parece ser apenas técnico, de tal forma que não são muitos os que ambicionam (ou estão capacitados a) fazer parte delas (Freidson, 1986:204-5, apud Speranza, 1991: 480).

Longe de serem maniqueístas ou conspiratórias, essas reflexões foram cruciais para a fundamentação da análise sobre o monopólio profissional médico em bases políticas e sociais. Dito de outra forma, o profissionalismo não é um termo meramente descritivo, mas um conceito que traz enraizada a capacidade das lideranças profissionais de conquistar, manter e expandir status social e poder para seu grupo.

Assim, pode-se convencionar que o poder profissional apóia-se sobre o conhecimento científico especializado (Freidson, 1970a e b), ainda que não seja este seu único determinante, porém o estabelecimento da validade do conhecimento dos experts é um processo político e não somente intelectual (Rushmeier, 1986: 106, apud Speranza, 1991:479). O que se evidencia nessa discussão é que o controle monopólico sobre a produção do conhecimento técnico-científico e a distribuição de serviços não derivam automaticamente da especificidade atribuída ao conhecimento especializado e ao ideal de serviços.

Da mesma maneira, competência técnica especializada, cientificamente reconhecida, e deontologia de serviço de utilidade pública são, de fato, os dois cânones clássicos da definição de profissão, assim como a base dos princípios da autonomia técnica do médico, em nome da qual este profissional decide o que é melhor para o seu paciente, como seu le- 
gítimo representante, e, ao mesmo tempo, é autorizado como juiz inquestionável de suas próprias ações. Estas premissas são também os fundamentos ideológicos da assistência sanitária à população, que, para se concretizar enquanto tal, entretanto, teve que obter a sustentação política para a aprovação estatal da autonomia profissional antes de traduzir-se em poder profissional e controle de recursos (Björkman, 1990:317).

Portanto, na sua essência, o monopólio da medicina no setor saúde tem um caráter político, não apenas porque a garantia de sua institucionalização implica intervenção do Estado, mas principalmente porque estimula e favorece a mudança das formas de representação profissional em direção à centralização e inclusividade. Logo, diz respeito à profissão como uma entidade corporativa. Por outro lado, como analisa Speranza (1991), o fato de que os médicos não conseguiram atingir um pleno monopólio ocupacional em todas a sociedades, isto é, coroar com pleno sucesso seu projeto profissional, evidencia que na eficácia da ação coletiva influi uma série de circunstâncias culturais, sociais, políticas e organizativas, que apenas para fins analíticos podem ser separadas.

Entre as condições culturais estariam as propriedades formais do conhecimento técnico especializado, cuja base cognitiva deve ser suficientemente formalizada e codificada a fim de permitir uma padronização, o que significa a pretensão de uniformidade na formação dos profissionais, mas com alta taxa de diferença individual no cotidiano profissional; ou seja, a competência deve parecer igual para todos, mas a sua aplicação, longe de apresentar-se como um fato de rotina, deve enfatizar a exigência de alto grau de discernimento individual, o que é conseguido somente após um longo aprendizado (aquilo que se poderia definir como a concessão da 'medicina como arte') (Speranza, 1991:482).

No que concerne às circunstâncias sociais que influenciam o desenvolvimento do profissionalismo, têm particular rel evância as relações de poder entre profissionais e clientes eos conflitos intraprofissionais.

No primeiro caso, é importante distinguir entre o profissional como indivíduo e a profissão como uma entidade corporativa. A relação que o profissional individualmente estabelece com a clientela depende das características desta, isto é, a atitude muda segundo seja um paciente privado ou público, ou ainda uma multinacional (e, neste último caso, seguramente a desvantagem estará do lado do profis- sional) (Freidson, 1982:220-21, apud Speranza, 1991:482). Os conflitos diretos entre profissionais e clientes são mais recentes e ainda pouco estudados, de tal forma que não é possível ainda incluí-los como variáveis que influenciam o desenvolvimento do profissionalismo, mas vale a pena serem mencionados. Seu aumento se deve tanto à maior acessibilidade dos leigos à informação médica e melhora do nível educacional dos clientes, quanto à ação dos movimentos reivindicatórios e judiciários de clientes/consumidores, que começaram a pedir contas aos profissionais sobre seus atos.

Muito diferente, porém, é o discurso dirigido aos profissionais como entidades coletivas (corporativas) ou associações representativas, que envolve pelo menos duas temáticas diferentes (que via de regra se confundem): uma que diz respeito às formas organizativas de representação (inclusivas ou exclusivas) e outra que concerne aos problemas de estratificação interna dos profissionais que integram a associação (com a conseqüente diversidade de interesses).

A exigência de obter o monopólio é que estimula as organizações profissionais a serem inclusivas, isto é, tentar representar todos os profissionais do setor, quaisquer que sejam suas especialidades, o que, por outro lado, pode traduzir-se em fator de debilidade política e de instabilidade, uma vez que a heterogeneidade de interesses internos complica o processo de decision making coletivo. Portanto, a decisão de ser exclusiva ou inclusiva é uma opção política, a ser feita em específicos processos de negociação, pelas respectivas associações, em contextos históricos determinados. Além disso, numa perspectiva pluralista, a heterogeneidade dos clientes - quando estes possuírem peso similar, quando forem pessoas físicas em vez de grandes sociedades, isto é, atomizados - pode também traduzir-se em posição de força dos profissionais como grupo e constituir uma das fontes do seu poder (Speranza, 1991:483).

Um problema completamente diverso está referido à estratificação no interior das profissões, fonte potencial de conflitos intraprofissionais e que remete à segunda condição social relevante de influência sobre o profissionalismo, uma vez que atinge o seu core. $\mathrm{O}$ autor que enfrentou sistematicamente essa argumentação foi mesmo Freidson (1983, 1984), quando se contrapôs às teorias da desprofissionalização e da proletarização das profissões, como vimos, com a hipótese de uma crescente estratificação formal, interna à cada profissão, em três papéis distintos: docente-pesquisador universitário, gerente-administrador e praticante. 
Como bem analisa Speranza, os profundos diferenciais de prestígio, renda, poder e autoridade, inerentes a esses três diferentes papéis, atestam as dificuldades e os conflitos daí advindos, talvez muito profundos para serem contidos no interior da profissão como entidade coletiva. No caso da medicina, como admite o próprio Freidson (e a minha prática profissional confirma), é muito difícil que os médicos vejam seus colegas não praticantes (administradores e mesmo pesquisadores) como verdadeiros médicos e, portanto, verdadeiros colegas.

A terceira condição que interfere de forma decisiva no desenvolvimento do profissionalismo, inclusive determinando o tipo de profissionalismo resultante, é a cultura política prevalecente em um dado contexto, numa determinada sociedade, onde a questão central se refere às relações Estado/ profissão, que discutiremos mais adiante.

Os autores apontam que o século XIX, de uma maneira geral, foi bastante hostil ao profissionalismo, no sentido em que, mesmo em culturas políticas diversas, o privilégio de os profissionais (entre eles os médicos) atuarem como interlocutores preferenciais do Estado não se verifica. Os determinantes são variáveis, porém, e a específica história de cada sociedade particular explica as diferenças de institucionalização do profissionalismo médico encontradas em cada país.

A mudança é radical, entretanto, com a emergência do welfare state, onde a inserção da profissão médica e sua maior influência no setor sanitário tem um duplo caráter (Speranza, 1991:487): de um lado aumenta consideravelmente o número dos profissionais e do outro é legitimado ou reforçado o monopólio profissional no setor. A crescente oferta pública de serviços em atividades tradicionalmente consideradas de domínio profissional (como saúde e educação, onde as faculdades de medicina, reunindo as duas funções, foram as grandes beneficiárias) (Heideheimer, 1989) e o fato de que o Estado torna-se o maior empregador para os profissionais, além de aumentar bastante o seu número, protege as suas rendas das oscilações de mercado. Por outro lado, o Estado atua também como um legitimador e reforçador do monopólio profissional, ao avalizar o papel das associações oficiais no reconhecimento e avaliação dos seus pares (Larkin, 1988).

Por último, os autores destacam o caráter instrumental dos fatores organizativos na estruturação da ação coletiva profissional, que permitiu transformar os recursos (culturais, sociais e políticos), acumulados pelas profissões, em uma lógica de ação capaz de, com base nos seus fundamentos epistemológicos, chegar ao poder monopólico em setores específicos (Halliday, 1985:435-6, apud Speranza, 1991:487). Entretanto, no caso da profissão médica, os achados empíricos são contraditórios e a lógica geral - quanto mais uma profissão é organizada numa única associação amplamente representativa, capaz de ampla mobilização da categoria, mais influência terá sobre o poder público - parece não funcionar plenamente, pelo fato de que a necessidade de ser inclusiva por si só age como freio à mobilização, pela maior fragmentação e conseqüente complexidade do processo decisório interno.

Exemplos, como o dos EUA, confirmam em parte essa afirmação, uma vez que, apesar de visto como o país onde os médicos têm maior autonomia, cujas associações são as mais fortes e poderosas, é a sociedade onde a ênfase na especialização é a mais absoluta, o que levou a grande fragmentação interna da profissão e necessidade de coordenação através de organizações complexas onde os médicos são apenas uma pequena parte, uma vez que dirigidas por managers profissionais cada vez mais poderosos (Light \& Levine, 1988).

Em síntese, as divisões internas à profissão, das quais se aproveita ou não o poder estatal, em conjunturas específicas, são insuficientes para explicar ou obstaculizar um fenômeno complexo como o profissionalismo, assim como as teorias corporativas clássicas sozinhas não dão conta de ajudar a entender o processo de policy decision making setorial.

\section{As fronteiras móveis da regulação profissional}

A questão central embutida na discussão do profissionalismo em geral, e no sanitário em particular, que interessa sublinhar para a meIhor compreensão da estruturação e dinâmica do sistema de serviços de saúde, é referida à auto-regulação profissional dos médicos e sua inter-relação com as demais formas de regulação presentes na sociedade.

Embora para os próprios profissionais, e para alguns autores, a auto-regulação constitua o corolário natural da autoridade profissional, ou ainda um atributo inato do profissionalismo, na realidade ela constitui o resultado de um longo processo histórico de construção política e social, onde a inter-relação do Estado com a profissão médica é fundamental, e segundo o qual o Estado é a autoridade que pri- 
meiro concede o monopólio e a auto-regulação e depois proporciona (ou retira) os meios para exercê-lo e defendê-lo (Speranza, 1991:491-5).

O conceito de auto-regulação comporta duas dimensões analíticas que na prática confundem-se, porque estreitamente interrelacionadas. A primeira dimensão é oriunda da percepção tradicional da auto-regulação como referida aos mecanismos e processos formais de autogoverno por meio dos quais os profissionais controlam a admissão, a preparação e o comportamento (trabal hista e ético) dos próprios membros da corporação, de forma a sancionar eventuais erros e/ ou abusos. A segunda dimensão pode ser derivada de uma definição de auto-regulação mais centrada nos modelos de regulação geral da sociedade (Lange \& Regini, 1987a e b), isto é, uma específica modalidade de formação e gestão da política pública e parapública, através da qual são as profissões, e não o Estado ou o mercado, que determinam as características da oferta e a demanda, estabelecendo os critérios e as finalidades das organizações, do financiamento e da distribuição dos serviços profissionais (Speranza, 1991:489).

Obviamente, na prática, as duas dimensões imbricam-se de forma inexorável, inclusive porque a segunda extrai força e legitimidade da primeira, e, conseqüentemente, a liberdade concedida aos profissionais para estabelecer as decisões técnicas que regulam seu próprio trabalho torna-se, ou pode tornar-se, uma autorização para determinar também os fins e a alocação de recursos essenciais ao setor (Speranza, 1991:490).

A auto-regulação não é, porém, a única forma de regulação profissional existente, mesmo porque sozinha é insuficiente e está sempre integrada a alguma outra forma de regulação externa.

Na literatura sobre as profissões, distinguem-se três formas diversas de regulação burocrática, desregulação (ou regulação de mercado) e auto-regulação ou controle pelos pares (Freidson, 1983). Tais formas não diferem na essência dos três princípios possíveis de regulação social - a autoridade ou controle hierárquico, a troca e a solidariedade -, cada um dos quais traduzido, historicamente, em instituições regulativas diversas, respectivamente o Estado, o mercado e a comunidade (Lange \& Regini, 1987a, apud Schmitter \& Streeck, 1985).

Ainda que a auto-regulação profissional historicamente tenha perdido suas ligações com a comunidade social e estreitado seus laços com a comunidade dos colegas, que obviamente não é a mesma coisa, não pode ser considerada uma quarta modalidade diferente de regulação, uma vez que se trata de um processo de negociação no qual as profissões devem, por meio da luta política, primeiro convencer a elite dominante de que são capazes de regular o próprio setor e depois obter a autorização do Estado. Este é um longo processo político e social. Além disso, como vimos, a auto-regulação de uma profissão não requer apenas uma intervenção inicial do Estado, mas a persistência da atividade de regulação estatal a seu favor, defendendo-a de outros grupos de interesse concorrenciais e, portanto, de princípios reguladores que concorrem com ela (isto é, o mercado).

Assim, a regulação burocrática ocorre quando o Estado, ou as grandes sociedades privadas, é quem dita as normas que regulam o desenvolvimento do trabalho profissional. A esta forma de regulação estão submetidos não apenas os empregados de uma organização (pública ou privada), mas também os que trabalham em tempo parcial ou com determinadas formas de contrato para programas financiados e organizados publicamente (como, por exemplo, o Medicare e o Medicaid nos EUA). Entretanto, como assinalam alguns autores (Derber, 1982; Navarro, 1988), essa burocratização, ainda que seja um dos resultados indesejáveis do welfare state, não significa a perda da autonomia técnica (como ocorre com os trabalhadores manuais), embora a liberdade de decisão, em termos globais, seja mais circunscrita. Mesmo prescindindo do contexto de trabalho burocratizado, algumas temáticas podem ser objeto de regulação estatal mediante critérios externos gerais sobre as modalidades de trabal ho profissional, como no caso dos limites e restrições impostas à pesquisa e à experimentação médica em humanos.

A última forma de regulação profissional é a regulação do mercado, que nos últimos dez anos passou a ser referida como desregulação, mas com bem pouca precisão analítica. Neste caso, o controle da atividade profissional é feito por intermédio dos mecanismos de mercado, que pressupõem a abolição do monopólio técnico e introdução de mecanismos de concorrência no trabalho profissional.

Historicamente, o único período em que o profissionalismo foi regulado principalmente por meio dos critérios de mercado, juntamente com outros da comunidade, foi no final do século XVIII e início do XIX, no período imediatamente sucessivo à Revolução Francesa (1789) (Heidenheimer, 1989; Speranza, 1991). A diferença do que ocorre hoje, na chamada desregulação, é que durante aquele período os critérios de mercado foram utilizados com base em 
uma ideologia que tinha conotações fortemente populistas, igualitárias e democráticas. E, a partir de então, as profissões dirigiram toda sua ação, com sucesso variado mas sempre crescente, ao objetivo de conquistar nichos de atuação protegidos do mercado, obviamente com formas de exclusão da concorrência bastante diversas nos vários países, mas com resultados equivalentes: os monopólios profissionais reconhecidos pelo Estado. Com isto não se quer dizer, porém, que o mercado não tenha qualquer papel na regulação das atividades profissionais, mas simplesmente que os critérios de mercado não influíram significativamente na dimensão da auto-regulação que se refere ao controle, preparação e comportamento dos próprios membros (mesmo a questão quantitativa da oferta de profissionais, que em larga medida foge ao controle das próprias profissões, não pode ser considerada como permeada unicamente pelo mercado). O mesmo não se pode dizer, porém, da dimensão voltada para a formação e gestão da política pública, como veremos mais adiante, onde o denominado managed care (por exemplo com as Health Maintenance Organizations-HMOs, nos EUA) é um exemplo expressivo entre outros.

De uma maneira geral, pode-se afirmar que a regulação do mercado nunca foi suficiente e esteve sempre integrada àquela burocrática e mesmo à auto-regulação.

O que é importante destacar nesta discussão é que as fronteiras entre as várias formas de regulação são móveis e sujeitas à ação coletiva das profissões, ainda que não de forma exclusiva, e a mudança de ênfase numa ou noutra forma de regulação (por exemplo da de mercado para a auto-regulação - no século XIX - e, mais recentemente, a partir dos anos 60, da auto-regulação às formas burocráticas) são impulsionadas historicamente por meio de processos políticos e sociais. Assim, a intervenção de uma terceira parte (Estado ou seguros) nas relações entre os médicos e seus pacientes, as crises e calamidades (econômicas, epidemias, guerras), com as conseqüentes necessidades de investimentos especiais e/ ou controle dos gastos destinados à assistência sanitária, são fatores, internos e externos ao setor, historicamente determinados, que deslocaram a predominância de uma forma de regulação em favor de outra.

Além disso, partindo-se da análise de Lange \& Regini (1987a), já mencionados, é possível contaminar de forma positiva o debate e avançar nessa discussão.

Assim, aqueles autores definem como objeto da regulação um conjunto particular de ati- vidades e relações entre atores "tanto as quedizem respei to à esfera da produção quanto a da distribuição de recursos econômicos" e como regulação "os diversos modos como um determinado conjunto de atividades ou de relações entre atores écoordenado, os recursos consentâneos são al ocados e os conflitos inerentes, reais ou potenciais, são estruturados" (Lange \& Regini, 1987a:13). O conceito de regulação inter-relaciona, portanto, três dimensões: coordenação de atividades, alocação de recursos e administração de conflitos.

Por outro lado, quando um princípio ou critério de regulação está estreitamente associado a uma instituição particular, existe a tendência de imaginar que tal instituição se baseia apenas naquele princípio (por exemplo, imagina-se que o princípio de autoridade e controle hierárquico seja o único critério de regulação utilizado pelo Estado, ou mesmo que a auto-regulação seja o princípio por excelência da regulação profissional; ou ainda que mecanismos de troca sejam usados apenas pelo mercado), o que pode ofuscar uma característica fundamental de qualquer instituição: todas se baseiam num mix dos três tipos de regulação, diferenciando-se na medida em que um deles se caracteriza como critério dominante ou historicamente incorporado nelas como prevalente, mas nunca exclusivo (Lange \& Regini, 1987a:28).

Esta constatação leva a outra observação teórica e política importante, ressaltada pelos autores: o pressuposto de que certos critérios de regulação são impróprios para determinadas instituições (por exemplo, de que os mecanismos de intervenção estatal são incompatíveis com o mercado) é um juízo de valor ideológico pouco fundamentado analiticamente.

Esta afirmação é, entretanto, altamente difundida na literatura recente sobre as relações Estado/sociedade, mesmo em campo sanitário, que tende a enfatizar a invasão de campo ou o obscurecimento das fronteiras próprias das diversas instituições regulativas como resultado "de mudanças profundas, contradições ou pel o menos instabilidade" (Lange \& Regini, 1987a:19).

Porém, esclarecem os autores, longe de ser um sinal de instabilidade institucional, a invasão de campo ou a presença de princípios considerados impróprios são a norma em todas as áreas de atividades e de relações concernentes à produção e à distribuição de recursos. Cada uma dessas áreas, na realidade, baseia seu funcionamento normal na intervenção de um particular mix de instituições e de princípios de regulação, que interagem entre si, e as disfun- 
ções, as contradições ou as mudanças devem ser investigadas através de outras variáveis, no processo mesmo onde elas se inserem.

No que diz respeito especificamente à regulação através de grupos associativos ou de interesse, uma quarta modalidade de regulação social foi proposta por Schmitter \& Streeck (1985:67): a concertação organizativa, inspirada no princípio associativo, que consiste na “constituição de governos privados aos quais são del egadas (pelo Estado) responsabilidades públicas ... [na] ... tentativa de utilizar interesses de determinadas categorias para criar e manter uma ordem social geralmente aceita".

Lange \& Regini (1987a e b) questionam se de fato a concertação organizativa constitui uma nova modalidade de regulação ou se é apenas um específico mix das três formas existentes. E Speranza (1991:494) faz-se a mesma pergunta no que concerne à auto-regulação profissional nos sistemas sanitários.

O que os estudos empíricos demonstram é que, apesar dos pontos de contato entre a regulação através de grupos associativos e a auto-regulação, não se pode afirmar que as reflexões teóricas que servem para explicar uma possam ser transpostas automaticamente para a outra. Entretanto, pode-se ter por hipótese que, à semelhança da primeira, a segunda não tem uma "autonomia analítica ... nem tanto porque represente um mix deEstado, mercado e comunidade, mas porque constitui uma forma derivada da regulação estatal" (Speranza, 1991: 494).

Os estudos de casos confirmam essa hipótese, como demonstrou Döhler (1990), ao analisar as mudanças recentes na assistência sanitária em cinco países (EUA, Alemanha Ocidental, Inglaterra, França e Suíça) e evidenciar que não se comprova a tese habitual de que quanto maior é a distância dos médicos do wel fare state (leia-se, menor intervenção estatal), tanto mais pronunciada será a sua autonomia e vice-versa; além de que, em muitas sociedades (como por exemplo na Inglaterra), a posição de proeminência dos médicos nos sistemas sanitários foi conseguida não prescindindo do Estado, e sim por intermédio deste. Sendo assim, a dominância e, conseqüentemente, a auto-regulação médica não são inversamente proporcionais à intervenção estatal, mas, ao contrário, desenvolvem-se no longo prazo segundo o tipo de intervenção estatal (Larkin, 1988).

Portanto, as três formas tradicionais de regulação profissional (burocrática, de mercado e auto-regulação) não são alternativas entre si, mas sim concorrentes, combinando-se diver- samente no tempo e no espaço na regulação do profissionalismo. A auto-regulação e a regulação burocrática são diversas, entretanto, ainda que tenham vários pontos em comum, uma vez que a primeira é marcada desde a sua origem pela intervenção (reguladora) do Estado (Speranza, 1991; Heidenheimer, 1989), e a mobilidade de fronteiras entre elas demonstra quão desviante e ideológica é a afirmação de que quanto maior a intervenção estatal menor a autonomia profissional e vice-versa.

$\mathrm{Na}$ realidade, a questão é muito mais complexa: envolve desde as estratégias que as profissões elaboram para atingir seus objetivos (convencer a elite dominante e o público de sua imprescindibilidade e obter do Estado formas de monopólio e auto-regulação), até a transformação das formas de representação necessárias para tal (de exclusiva a inclusivas); os recursos a serem utilizados (competência técnica, desenvolvimento científico, clientes atomizados, cultura política de welfare state); os vínculos e obstáculos diversos que devem ser enfrentados (profissões concorrenciais, fraturas internas, organizações coletivas dos clientes, culturas políticas igualitárias), mas também, o tipo específico de intervenção estatal implementada em momentos históricos dados.

As mutáveis relações entre a profissão médica e o Estado na formulação/ implementação da política de saúde

A relação intervenção estatal/autonomia profissional não tem um sentido único, nem é uniforme ou imutável no tempo, sendo muito mais complexa que um jogo de soma zero, podendose afirmar com Johnson (Johnson, 1982, apud Speranza, 1991:497) que o profissionalismo, quando existe, é um fenômeno que integra o processo de formação do próprio Estado. A história dessa relação, entretanto, não é apenas o resultado nem de uma crescente intervenção estatal, em campos outrora autônomos, nem de enfrentamentos entre o Estado e as profissões, devido a essa intromissão indevida. Da mesma maneira, o que se tornou poder e funções do Estado, em campos específicos, não derivam de algum atributo estatal prévio, mas representam o efeito das relações que o Estado mantém com as profissões em sociedades específicas.

Para Heidenheimer (1989:529), o termo profissões de status (status professions) é o mais apropriado para designar os médicos, uma vez que captura a característica essencial 
que os distingue (juntamente com os padres e advogados) das demais profissões, isto é, serem herdeiros das tradições das chamadas profissões eruditas (learned professions) da Europa pré-industrial, em contraste com as profissões ocupacionais (occupational professions), que são mais recentes e vinculadas a critérios mais modernos de profissionalização.

Essas profissões de status, segundo o autor, sempre foram de grande importância em vários tipos de regime: centrais nas questões relacionadas às políticas de população, quando da construção, eficácia e legitimação dos Estados absolutistas; foram igualmente cruciais, mais tarde, na sustentação e legitimação da governabilidade do Estado liberal, assim como se desenvolveram com a transição para os welfare states. Ainda que de forma derivada, seu status é anterior ao Estado moderno, mas, no caso da área de saúde, a profissão médica floresceu a partir da priorização pelo Estado das questões sanitárias e da destinação de altas somas do orçamento público para financiar as atividades no campo da saúde. Ou seja, o profissionalismo médico se desenvolveu par e passo à construção do Estado e à modernização capitalista, ao mesmo tempo em que a extensão da assistência médica reforçou o welfare e deu sustentação à manutenção da população produtiva de várias nações (Heidenheimer, 1989:530).

Como Freidson apontou, e recuperado por Heidenheimer, o principal problema teórico nas reflexões sobre o profissionalismo é definilo a partir de um conceito genérico de profissão, em vez de apreendê-lo como um conceito mutável historicamente, com raízes particulares nas sociedades industriais, que foram fortemente influenciadas pelas instituições angloamericanas. Sendo assim, o conceito freidsoniano das profissões como 'agentes do conhecimento formal' e a discussão dos "pré-requisitos materiais para essa relação de agenciamento são bastante úteis (Heidenheimer, 1989:531). Porém, para Heidenheimer, o que falta em geral nessas reflexões é desenvolver, de forma análoga, uma análise dos determinantes políticos das formas alternativas de agenciamento profissional.

Apesar das características similares e inúmeras identidades do profissionalismo médico em diversos países, a estruturação profissional nos sistemas de saú de específicos mudou historicamente no tempo, em cada sociedade, assim como alteraram-se as relações entre médicos/ clientes e médicos/ Estado. Analogamente, é através de suas inter-relações com o Estado que a profissão médica tem desempenhado importante papel na modelagem dos diferen- tes perfis das políticas nacionais de saúde. $O$ argumento central defendido por Heidenheimer (1989) é que as diferentes trajetórias históricas na relação Estado/ profissões podem ajudar a explicar as diferenças na política sanitária nos diversos países.

De crucial importância, portanto, é analisar como as diferentes nações concederam, retiraram e/ ou voltaram a formalizar a concessão de autonomia à profissão médica, pois, enquanto a dinâmica dos novos descobrimentos das pesquisas e novas tecnologias penetrava cada vez mais o setor sanitário, encorajando convergências tanto nos métodos científicos a serem utilizados na assistência, quanto na logística dos sistemas de serviços de saúde em geral, as relações entre Estado/ profissão, profissão/clientes e clientes-eleitores/governos divergiram significativamente nos diversos países.

No que diz respeito aos consumidores, em alguns países europeus houve época em que foram muito mais organizados que os próprios médicos. As Friendly Soci eties britânicas, por exemplo, no século XIX, chegaram a reunir cerca de três milhões de filiados, majoritariamente trabalhadores usuários dos serviços de saúde, e conseguiram desempenhar um forte poder de barganha com os médicos contratados para o atendimento de seus membros. Já na Alemanha Ocidental, pioneira na institucionalização do sistema de pagamento por terceiros (ou de terceiro pagador), fundos de doença similares aos ingleses foram escolhidos, em 1883, como intermediários na implementação do seguro-doença compulsório, por meio do qual os Fundos negociavam com os médicose o governo em nome de seus membros. Esses grupos perderam espaço de negociação frente à revolução científica na medicina, o desenvolvimento das técnicas gerenciais dos fundos e à intermediação das grandes seguradoras comerciais.

Os médicos americanos, por sua vez, mediante o poder de fogo da American Medical Association-AMA, foram tenazmente contra, não apenas à criação de qual quer seguro estatal, mesmo à moda alemã, mas também se opuseram aos grupos voluntários do sistema de terceiro pagador. Até 1940, os membros da AMA se recusavam a atender pacientes dos planos de seguro de pré-pagamento e, como represália, negavam o uso dos serviços hospitalares àqueles médicos que desafiassem essa norma (Heidenheimer, 1975:16). 


\section{Para concluir}

De toda essa discussão, o que é importante reter pode ser sintetizado como se segue:

A natureza e tipo de intervenção estatal na área sanitária é crucial para a apreensão e compreensão dos determinantes estruturais de qualquer sistema de serviços de saúde e, longe de ter um único padrão de desenvolvimento linear e progressivo, esteve sempre sujeita a variáveis históricas, tanto internas, como externas ao campo setorial, às quais cada sociedade respondeu de forma muito própria.

A centralidade do médico como ator político pode ser atestada em termos históricos em praticamente todos os sistemas de saúde, entretanto, os graus de autonomia e autogoverno profissional conquistados por esses profissionais são resultado do tipo de tutela que o Estado outorgou à profissão, em processos políticos específicos, de longo prazo, cuja dinâmica própria em cada país recomenda cautela com qualquer afirmação mais generalizante. A forma e alcance dessa concessão estatal também diferiu no tempo e no espaço, em cada sociedade, e altera-se continuamente na medida em que se transforma o próprio Estado e/ ou emergem condições em que se manifeste necessidade de maior controle e/ ou regulação.

Essa mobilidade de fronteiras (regulatórias e/ ou de intervenção estatal) é temperada por variáveis muitas vezes externas ao setor saúde e talvez seja a única característica generalizável para quaisquer sistemas de saúde, cujas dinâmicas são especificidades de cada sociedade, inseridos que são nos respectivos sistemas políticos.

A emergência do welfare state foi um divisor de águas importante na relação entre os médicos, o Estado e a formulação/implementação de políticas de saúde, uma vez que aumentou consideravelmente o número de profissionais e consolidou os sistemas de serviços de saúde, sobretudo de assistência médica. A crescente oferta pública de serviços e o fato de o Estado tornar-se o maior empregador de profissionais protegeram suas rendas das oscilações de mercado, por um lado, e reforçaram o poder monopólico dos médicos, por outro, ao avalizar o papel das associações profissionais no policy decision making setorial e no reconhecimento e avaliação dos seus pares. Ou seja, a profissão médica floresceu a partir da priorização pelo Estado das questões sanitárias e da destinação de al tas somas do orçamento público para financiar atividades no campo da saúde. Essa relação médicos/Estado, mediada pela política de saúde, é mutável historicamen- te no tempo e no espaço e, apesar da aparente convergência, tanto nos métodos científicos a serem utilizados na assistência, quanto na logística dos sistemas de serviços de saúde em geral, as relações Estado/ profissão, profissão/ clientes e cidadãos/ governos divergiram significativamente nos diversos países.

A crise fiscal do Estado detonou o questionamento das premissas que orientaram as políticas de saúde expansionistas do pós-guerras, colocando em discussão o funcionamento dos serviços de saúde, com especial ênfase, porém, no trabalho médico, tendo como finalidade última a retirada da garantia pelo Estado tanto da proteção de rendas profissionais (seja por meio de assalariamento direto, ou de reembolsos, subsídios ou incentivos), quanto de nichos protegidos do mercado de serviços de saúde.

Em outras palavras, a específica forma de modernização capitalista setorial, sob a égide da hegemonia americana, privilegiando o investimento tecnológico (deslocando, portanto, o critério prévio de valor científico), desencadeou desenvolvimentos no âmbito profissional e dos serviços de saúde - crescente complexidade técnica e organizacional; privilégio das contínuas especializações e do setor hospitalar; aparecimento e crescimento rápido das grandes corporações de assistência médica; aumento contínuo dos custos setoriais - que exacerbaram as críticas à direita e à esquerda e encaminharam o debate no sentido da restrição do poder profissional, como justificativa, porém, primeiro para a contenção de custos e depois para a restrição do direito de cidadania de acesso aos serviços de saúde. 


\section{Referências}

BECKER, H. S., 1970. Sociological Work. Chicago: Aldine Publishing.

BECKER, H. S., 1964. The Other Side: Perspectives on Deviance. New York: Free Press.

BECKER, H. S., 1963. The Outsiders. Glencoe: Free Press.

BELL, D., 1976. The Cultural Contradictions of Capitalism. New York: Basic Books.

BJÖRKM AN, J. W., 1990. Politizzazione della medicina e sanitarizzazione della politica: il potere dei medici negli Stati Uniti. In: Medici e Stato nel Mondo Occidentale - Cultura Politica e Professionalitá Medica (G. Freddi, org.), pp. 305-353, Bologna: II Mulino.

COBURN, D., 1992. Freidson then and now: an internalist critique of Freidson's past and present views of the medical prodession. International Journal of Health Services, 22:497-512.

DERBER, C., 1982. Toward a new theory of professionals as workers: advanced capitalism and post-industrial labor. In: Professional as Workers: Mental Lsabor in Advanced Capitalisms (C. Derber, ed.), pp. 193-208, Boston: G. K. Hall and Co.

DÖHLER, M., 1990. L'autonomia professionale dei medici e lo stato sociale: problema o soluzione? In: Medici e Stato nel Mondo Occidentale-Cultura Politica e Professionalitá Medica (G. Freddi, org.), pp. 49-78, Bologna: Il Mulino.

DONNANGELO, M. C. F. \& PEREIRA, L., 1976. Saúdee Sociedade. São Paulo: Duas Cidades.

DONNANGELO, M. C. F., 1975. Medicina e Sociedade São Paulo: Pioneira.

FREIDSON, E., 1986. Professional Power: A Study of the Institutionalization of Formal Knowledge. Chicago: Chicago University Press.

FREIDSON, E., 1985. The reorganization of the medical profession. Medical Care Review, 42:11-35.

FREIDSON, E., 1984. The changing nature of professional control. Annual Review of Sociology, 10:1-20.

FREIDSON, E., 1983. The reorganization of the professions by regulation. Law and Human Behavior, 2/ 3:279-290.

FREIDSON, E., 1970a. Profession of Medicine: A Study of the Sociology of Applied Knowledge. New York: Dodd, Mead \& Company.

FREIDSON, E., 1970b. Professional Dominance: The Social Structure of Medical Care. Chicago: Atherton Press.

FRIEDMAN, M., 1962. Capitalism and Freedom. Chicago: Chicago University Press.

HAUG, M. R., 1988. A re-examination of the hypotesis of physician deprofessionalization. The Milbank Quarterly, 66(suppl.2):48-56.

HAUG, M. R., 1981. The sociological approach to self regulation. In: Regulating the Profession (R. D. Blair \& S Rubin, eds.), pp 61-80, Lexington: Lexington Books.

HAUG, M. R., 1973. Deprofessionalization: an alternate hypothesis for the future. Sociological $\mathrm{Re}$ view Monograph, 20:195-211.
HEIDENHEIMER, A. J., 1989. Professional knowledge and the state policy in comparative historical perpective: law and medicine in Britain, Germany and the United States. International Social Science Journal, 122:529-553.

HEIDENHEIMER, A. J., 1975. Health care: delivery options and policy constraints. In: Comparative Public Policy - The Politcs of Social Choice in Europeand America (A. J. Heidenheimer, H. Heclo \& C. T. Adams, eds.), pp 13-43, New York: St. Martin's Press.

HUGHES, E. C., 1971. The Sociological Eye: Selected Papers on Work, Self and the Study of Society. Chicago: Aldine-Atherton.

IM MERGUT, E. M., 1992. The Political Construction of Interest. Cambridge: Cambridge University Press.

KLEGON, D., 1978. The sociology of professions: an emerging perspective. Sociology of Work and Occupations, 3:259-283.

LABRA, M. E. \& BUSS, P. M., 1995. Introdução. In: Sistemas de Saúde; Continuidades e Mudanças (P. Buss \& M. E. Labra, orgs.), pp 9-28, Rio de Janeiro: Ed. Fiocruz/ São Paulo: Hucitec.

LABRA, M. E., 1995a. As políticas de saúde no Chile: entre a razão e a força. In: Sistemas de Saúde; Continuidades e Mudanças (P. Buss \& M. E. Labra, orgs.), pp. 103-152, Rio de Janeiro: Fiocruz/ São Paulo: Hucitec.

LABRA, M. E., 1995b. El Sistema de Salud. Santiago: La Epoca.

LANGE, P. \& REGINI, M., 1987a. Stato e Regolazione Sociale - Nuove Prospettive sul Caso Italiano. Bologna: II Mulino.

LANGE, P. \& REGINI, M., 1987b. Regolazione sociale e politiche pubbliche: schemi analitici per lo studio del caso italiano. Stato e Mercato, 19:97-121.

LARKIN, G., 1988. Medical dominance in Britain: image and historical reality. The Milbank Quarterly, 66(suppl.2):117-132.

LIGHT, D. W. \& LEVINE, S., 1988. The changing charater of the medical profession: a theorethical overview. The Milbank Quarterly, 66(suppl.2):1029.

LIGHT, D. W. \& SCHULLER, A., 1986. Political Values and Health Care: The German Experience. Cambridge: MIT Press.

LIGHT, D. W., 1986. Corpore medicine for profit. Scientific American, 255:38-45.

MCKINLAY, J. B. \& STOECKLE, J. D., 1988. Corporatization and the social transformation of doctoring. International Journal of Health Services, 18:191-206.

MCKINLAY, J. B. \& ARCHES, J., 1985. Towards the proletarianization of physicians. International Journal of Health Services, 15:161-95.

MCKINLAY, J. B., 1977. The business of good doctoring or doctoring as good business: reflections on Freidson's view of the medical game. International Journal of Health Services 7:459-87. 
MECHANIC, 1991. Sources of countervailing power in medicine. Journal of Health Politics, Policy and Law, 16:485-498.

NAVARRO, V., 1988. Professional dominance or proletarization, neither. The Milbank Quarterly, 66(suppl.2):57-75.

SACKS, M., 1983. Removing the blinkers? A critique of recent contributions to the sociology of professions. Sociological Review, 1:1-21.

SCHMITTER, P. \& STREECK, W., 1985. Comunitá, mercato, Stato e associazioni? II possible contributo dei governi private all'ordine sociale. Stato e Mercato, 3:47-86.

SPERANZA, L., 1991. Sociologia e political economy delle professioni. Stato e Mercato, 33:477-501.

WOLINSKY, F. D., 1988. The professional dominance perspective, revisited. The Milbank Quarterly, 66(suppl.2):33-47. 